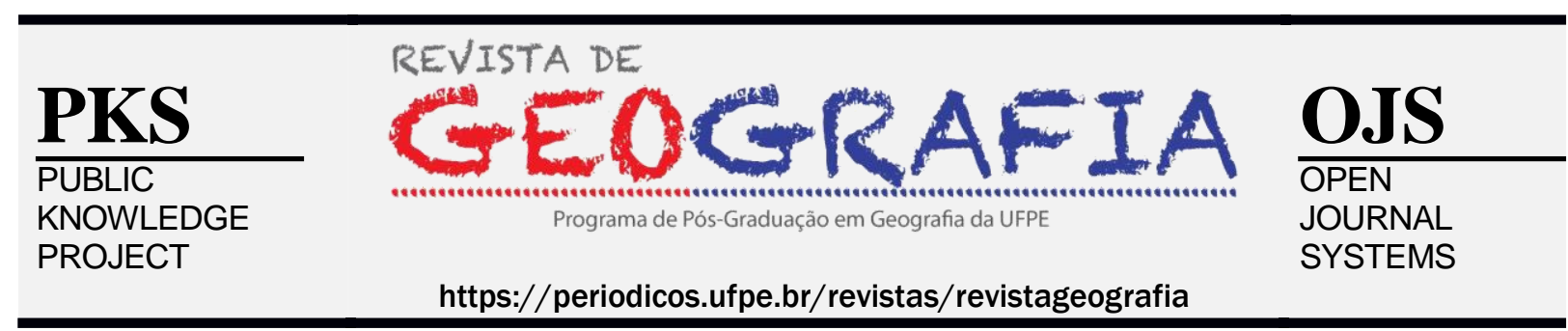

\title{
A REDE DE PRODUÇÃO DE BIOCOMBUSTÍVEIS DA REGIÃO SUL DO BRASIL
}

\author{
Adriano Ferreira Guimarães ${ }^{1}$, Ana Paula Colavite ${ }^{2}$, Edson Antônio da Silva ${ }^{3}$
}

\begin{abstract}
${ }^{1}$ Mestre pelo Programa de Pós-graduação a nível de mestrado profissional em Bioenergia (Unioeste, 2017). Email: adrianofguimaraesguimaraes@gmail.com.

${ }^{2}$ Professora adjunta e docente permanente do Programa de Pos-graduação Interdisciplinar Sociedade e Desenvolvimento da Universidade Estadual do Paraná. E-mail: apcolavite@ hotmail.com.

3 Professor Associado e docente permanente dos Programas de Pós-graduação em Engenharia Química e Bioenergia da Universidade Estadual do Oeste do Paraná. E-mail: edsondeq@hotmail.com.
\end{abstract}

Artigo recebido em 30/05/2018 e aceito em 04/12/2019

\begin{abstract}
RESUMO
O Brasil é o segundo maior produtor de biocombustíveis do mundo, sendo a soja e a cana-de-açúcar as matériasprimas mais utilizadas no processo. O objetivo da pesquisa concentrou-se na análise da distribuição geográfica das usinas produtoras de biocombustíveis da Região Sul do país, bem como na influência de fatores naturais na disponibilidade de matéria-prima, na estrutura de transporte para o escoamento dessa produção e no potencial de produção a partir da gordura animal. Partiu-se da localização das usinas cadastradas na Agência Nacional do Petróleo, Gás Natural e Biocombustíveis (ANP), às quais foram atrelados os dados de disponibilidade de matériaprima, malhas de transportes e produção animal. Conforme a ANP, a região possui 48 usinas cadastradas em sua plataforma, das quais 35 estão localizadas no estado do Paraná, 12 no Rio Grande do Sul e uma em Santa Catarina. A Região Sul é grande produtora de soja, cana-de-açúcar e gordura animal, demonstrando elevado potencial para a produção de biocombustíveis a partir dessas matérias-primas, o que ainda não é totalmente explorado.
\end{abstract}

Palavras-chave: Matriz energética; Energia renovável; Distribuição espacial; Mapeamento.

\section{THE BIOFUELS PRODUCTION NETWORK OF SOUTHERN BRAZIL}

\begin{abstract}
Brazil is the second largest producer of biofuels in the world, with soybeans and sugarcane being the most used raw materials in the process. The objective of this research is to analyze the geographic distribution of biofuel production plants in the Southern Region of the country, as well as the influence of natural factors on the availability of raw material, on the transport structure for the outflow of this production and on the potential Production from animal fat. Starting from the location of the plants registered in the National Agency of Petroleum, Natural Gas and Biofuels, which were linked the availability data of raw material, transport networks and animal production. According to the agency, the region has 48 plants registered in its platform, of which 35 are located in the state of Paraná, 12 in Rio Grande do Sul, and one in Santa Catarina. The Southern Region is a major producer of soybeans, sugar cane and animal fat, demonstrating a high potential for the production of biofuels from these raw materials, which is not yet fully exploited.
\end{abstract}

Keywords: Energy matrix; Renewable energy; Spatial distribution; Mapping. 


\section{INTRODUÇÃO}

A partir da Revolução Industrial, o desenvolvimento das nações passou a associar-se diretamente com o controle e a disponibilidade dos inúmeros sistemas energéticos. As sociedades contemporâneas dependem largamente de uma complexa rede de tecnologias para extrair, transformar, entregar e utilizar as diferentes fontes de energia para suprir os padrões da vida hodierna, sendo esta rede considerada como um fator limitante ou impulsionante no processo de desenvolvimento de uma sociedade.

A demanda por energia vem crescendo com o aumento da população mundial e com a ampliação dos processos industriais, o que constitui um desafio em termos de planejamento das cadeias produtivas, associadas à produção e distribuição de energia, bem como a gestão dos impactos socioambientais envolvidos.

As matrizes energéticas mais utilizadas no mundo são derivadas de fontes fósseis, das quais o petróleo, o carvão mineral e o gás natural representam a maior parcela da energia produzida no planeta. Estas são reservas naturais finitas e tendem a ficarem escassas, portanto há a eminente necessidade de investimento em novas fontes de energia, especialmente nas renováveis provenientes de usinas hidrelétricas, geotérmicas, eólicas, solares, maremotrizes e também através da biomassa.

O Brasil é considerado um dos pioneiros nos estudos de bioenergia através da biomassa, desde a década de 1970, sendo o país que mais investiu em biocombustíveis no mundo, até perder a liderança para os Estados Unidos nas duas últimas décadas (BIODIESELBR, 2011). O país apresenta este status de destaque em decorrência da extensão territorial e das condições morfoclimáticas, propícias à produção de biomassa para fins alimentares, químicos e energéticos (HOLANDA, 2004).

Duas questões espaciais apresentam alta relevância na produção de biocombustíveis: a existência de áreas disponíveis para obtenção de matéria-prima; e o sistema viário para o escoamento da produção. Juntos formam uma rede da produção e do consumo do biocombustível na qual se interligam a oferta de matéria-prima e os meios de produção e escoamento. Cada componente articula-se em uma dada escala, com inúmeros elementos e de diferentes formas dentro da rede geográfica estabelecida.

O objetivo da pesquisa concentrou-se na análise da distribuição geográfica das usinas produtoras de biocombustíveis da Região Sul do país (figura 1), bem como na influência de fatores naturais na disponibilidade de matéria-prima, na estrutura de transporte para o 
escoamento dessa produção e, no potencial de produção a partir da gordura animal. Considerouse a distribuição por municípios e a articulação regional na forma de redes de produção.

Figura 1 - Mapa da área de estudo: Região Sul do Brasil

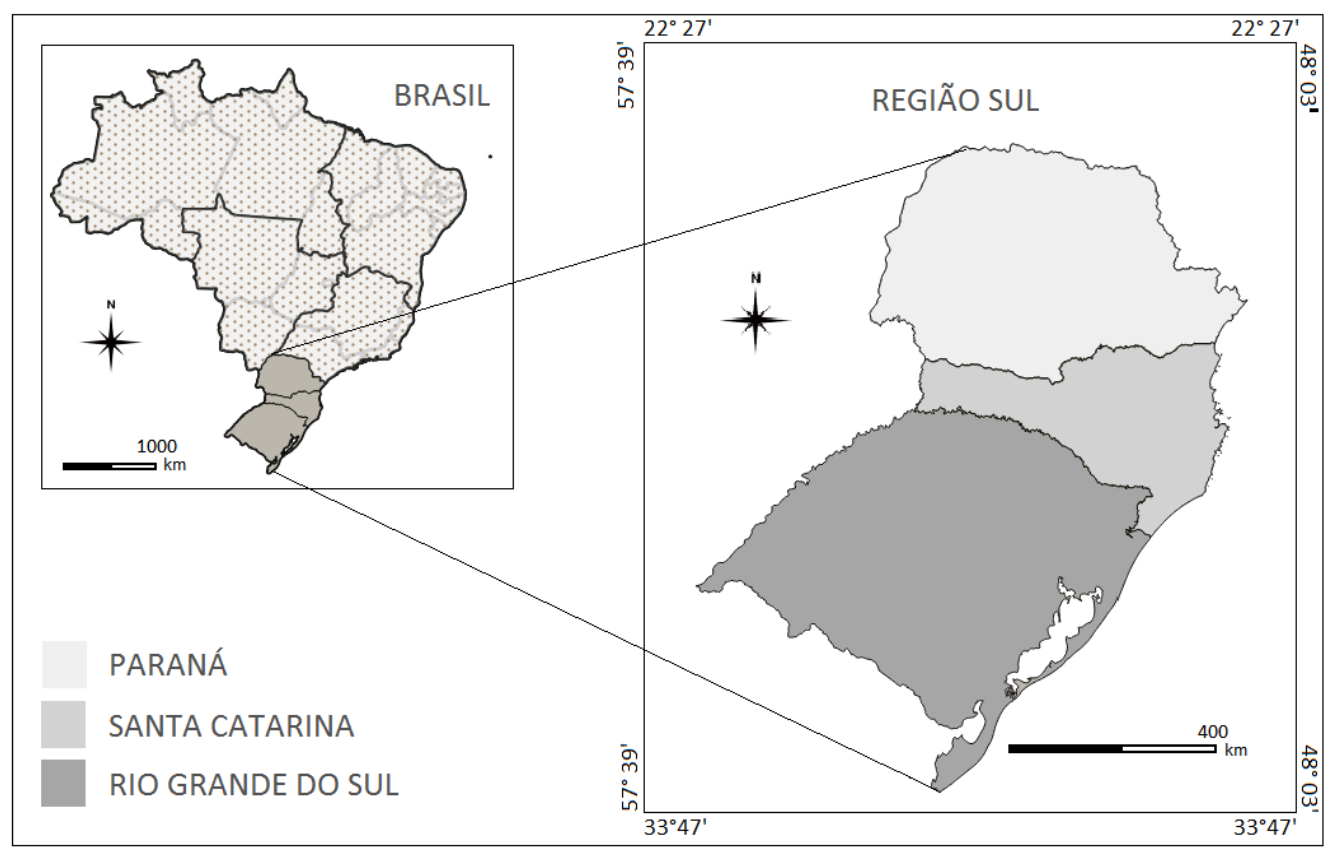

Fonte: Base cartográfica (IBGE, 2015a)

Org.: GUIMARÃES (2016)

A pesquisa seguiu o método analítico, pautado em dados qualitativos e quantitativos, e seu desenvolvimento procedeu em três etapas conforme descrito:

$1^{\circ}$ - Traçou-se um panorama da atual situação de desenvolvimento dos biocombustíveis no Brasil e no mundo.

$2^{\circ}$ - Elaborou-se uma listagem das usinas produtoras de biocombustíveis cadastradas na Agência Nacional do Petróleo, Gás Natural e Biocombustíveis (ANP), com a classificação da matéria-prima e a quantidade de biocombustíveis produzidos.

$3^{\circ}$ - Construiu-se um banco de dados em QGIS, onde foram espacializadas as usinas produtoras de biocombustíveis e a produção agrícola (soja e cana-de-açúcar, principais matérias-primas da Região Sul). Com base nesses dados, foram produzidos mapas temáticos que auxiliaram o desenvolvimento da pesquisa e a análise dos resultados.

\section{STATUS DA PRODUÇÃO MUNDIAL DE BIOCOMBUSTÍVEIS E A REALIDADE BRASILEIRA}

Na atualidade, o petróleo é, sem dúvida, a matriz energética de maior destaque no cenário mundial, sendo a mais utilizada, seguida do carvão mineral e do gás natural, os quais 
juntos somam mais de $80 \%$ de toda energia consumida no mundo. Costa (2011, p. 21) destaca que "o petróleo modificou significativamente a economia, a sociedade e o espaço dos países produtores do mundo em desenvolvimento nos últimos dois séculos", além disso, o petróleo foi o protagonista da Segunda Revolução Industrial.

Porém, desde a criação dos motores a diesel (1911), já se assinalava para a possibilidade do uso de óleos vegetais como matéria-prima (SASTRY; MURTHY, 2012). De acordo com Knothe (2002), na década de 1930 o governo francês incentivava experiências com óleos de amendoim, com intuito de obter independência energética das principais potências.

Com a Segunda Guerra Mundial, o abastecimento de petróleo foi cortado e o óleo vegetal foi utilizado como substituto. Com o fim da guerra e o reabastecimento do petróleo o desenvolvimento dos combustíveis de origem vegetal foi praticamente abandonado, até a crise energética entre os anos 1973 e 1974, quando ocorreu uma reativação no uso das energias renováveis. Como reflexo e alternativa de enfrentamento à crise, o Brasil lançou o Programa Nacional do Álcool (Proálcool) em 1975.

Ainda que a partir da década de 1970 os combustíveis de origem vegetal tenham adquirido destaque, com o crescimento demográfico e a ampliação dos processos de urbanização e industrialização houve aumento significativo no consumo de combustíveis fósseis e, consequentemente, na emissão de gases do efeito estufa (FREITAS, FREDO, 2005). A preocupação com a contínua ampliação da poluição atmosférica levou os países integrantes da ONU a assinarem o Protocolo de Kyoto (1997), com o compromisso de reduzir a emissão de gases do efeito estufa.

Visando atender ao compromisso assumido, muitos países têm buscado fontes de energia menos poluentes, como a hidrelétrica, a eólica, a solar, a maremotriz, a geotérmica e a energia proveniente da biomassa, sendo esta a mais utilizada nos países em desenvolvimento (figura 2). A biomassa consiste em todo combustível proveniente da matéria orgânica, com origem: vegetal (plantas oleaginosas e aminoácidos); natural (biogás) ou; em processos industriais (resíduos orgânicos, gorduras animais e residuais).

O biocombustível é derivado da biomassa e apresenta inúmeras classificações. Leite e Leal (2007) explicam que os biocombustíveis podem ser divididos em dois grupos: os etanóis produzidos a partir do açúcar e do amido (cana, beterraba, milho e mandioca) e; o biodiesel produzido através de óleos vegetais e de gordura animal e residual (soja, mamona, dendê, sebo bovino, óleo de frituras, entre outros). 
Figura 2 - Gráficos das principais matrizes energéticas mundiais

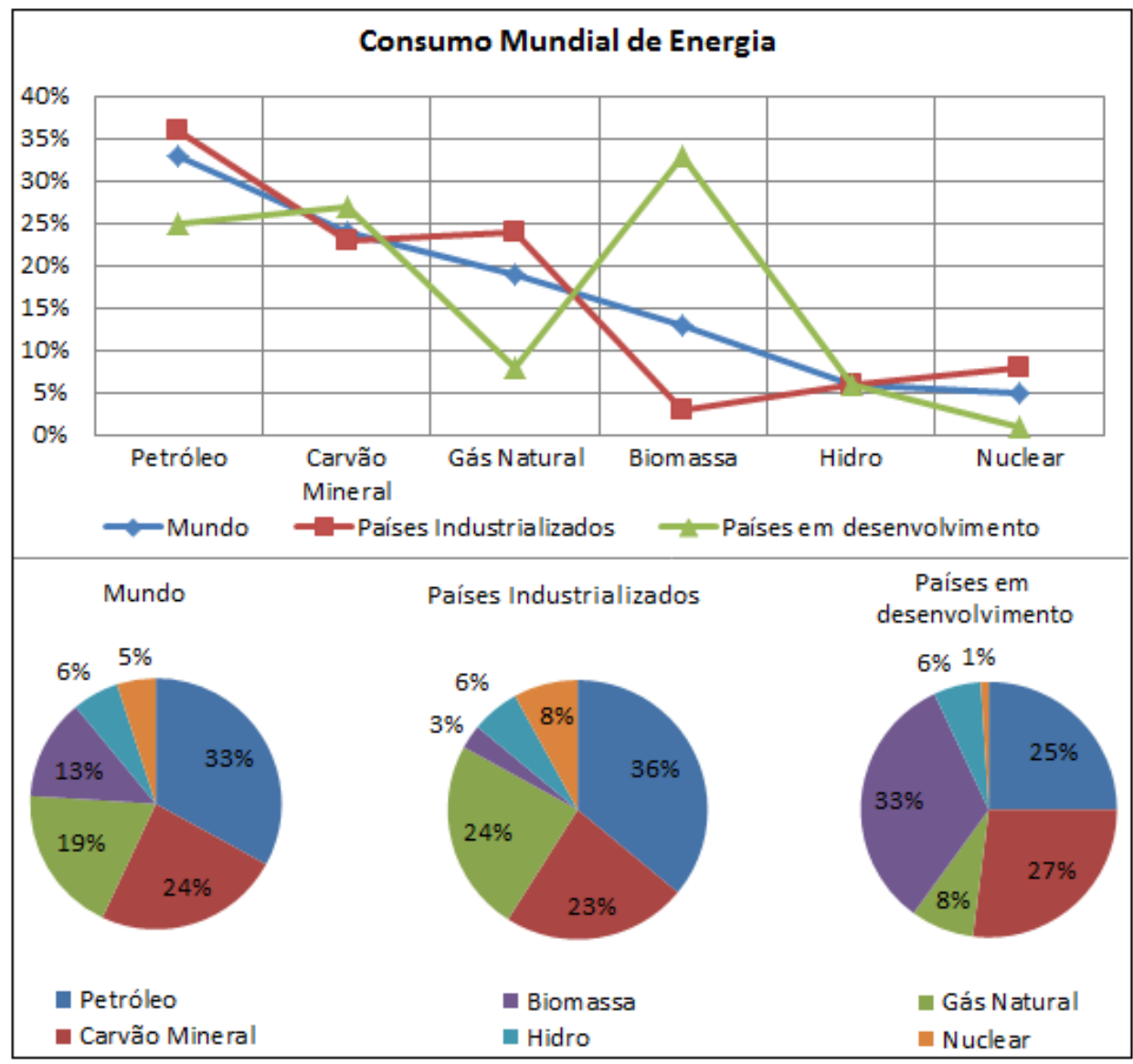

Fonte: HALL e HOUSE (1995)

Adaptação: GUIMARÃES (2016)

O Brasil é um dos maiores produtores de biocombustíveis, ficando atrás apenas dos Estados Unidos. A Alemanha, a França e a China figuram como $3^{\circ}, 4^{\circ}$ e $5^{\circ}$ colocados em produção de biocombustíveis, embora distantes dos dois primeiros (figura 3). Analisando a situação conjuntural, Tolmasquim et. al. (2007) afirmam que os países que se posicionarem com maior acesso e investimento nos recursos energéticos alternativos, de baixo custo e menor impacto ambiental, obterão vantagens no processo de desenvolvimento socioeconômico, já que o domínio de meios de produção tende a promover a segurança e a estabilidade energética necessárias.

Para a produção do biodiesel existem diversas matérias-primas, tais como óleos vegetais, gorduras animais e residuais, por meio de diversos processos. Na forma líquida (etanóis e biodiesel), gasosa (gás natural) ou sólida (bagaços, resíduos de biomassa, briquetes, piquetes). E, embora haja diversas matérias-primas para a produção do biodiesel, o proveniente da soja é o de maior destaque em nível mundial. 
Figura 3 - Maiores produtores de biocombustíveis do mundo em 2010

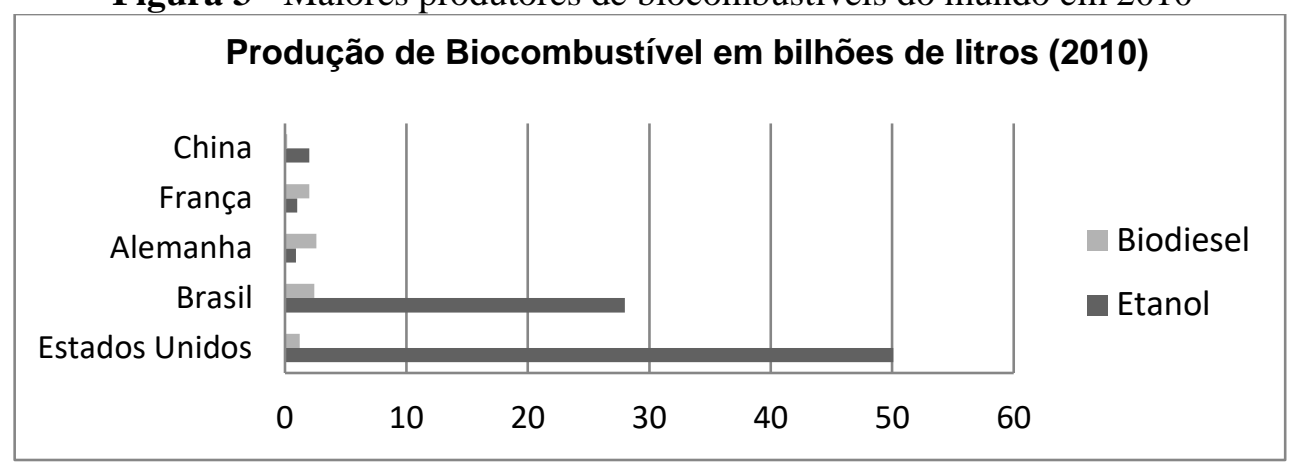

Fonte: BIODIELBR (2015)

Adaptação: GUIMARÃES (2016)

A utilização de biodiesel vem apresentando um potencial promissor em nível mundial, com mercado em plena expansão, pois apresenta redução qualitativa e quantitativa dos níveis de poluição ambiental e constitui uma fonte estratégica de energia renovável em substituição aos derivados do petróleo (FERRARI et. al. 2005).

Porém, a produção brasileira de biodiesel a partir da soja não tem obtido o merecido destaque e interesse no mercado internacional, em decorrência do conflito que gera com a produção e exportação de gêneros alimentícios (KOHLHEPP, 2010). Ainda que a soja seja utilizada em larga escala para a produção de biocombustíveis, no Brasil a produção de maior expressividade segue com o etanol derivado da cana-de-açúcar.

Conforme a EMBRAPA (2009), o Brasil é o maior produtor mundial de cana-deaçúcar, liderando o mercado mundial do etanol e da tecnologia aplicada a esse, e apresenta mais de sete milhões de hectares plantados, produzindo mais de 480 milhões de toneladas de cana por ano. O estado de São Paulo é o maior produtor brasileiro de cana-de-açúcar, seguido pelo estado do Paraná (ÚNICA, 2016).

Com relação à soja, o Brasil é o segundo maior produtor mundial, atrás dos Estados Unidos. De acordo com a ANP (2015), esta matéria-prima é responsável por mais de 82\% da produção de biodiesel no país, seguida da gordura bovina, com 16\%. Uma pequena parcela da soja produzida no Brasil é destinada à fabricação do biodiesel e, segundo o Ministério da Agricultura, a produção de biodiesel através da soja é capaz de reduzir em até 78\% as emissões de gases causadores do efeito estufa na atmosfera.

Segundo o IBGE (2013), existem 72,4 milhões de hectares destinados à agricultura no Brasil, dos quais 27,9 milhões (38,58\%) são destinados à soja e 10,2 milhões (14,11\%) à canade-açúcar. De acordo com a Secretaria de Estado da Agricultura e do Abastecimento - SEAB 
(2016), o Paraná teve um acréscimo de 33\% de área plantada entre 2006 e 2015, passando de 3,93 para 5,24 milhões de hectares.

É evidente o destaque do Brasil na produção mundial de biocombustíveis, sobretudo através da cana-de-açúcar e da soja, porém, outras matérias-primas têm se destacado na produção, como as gorduras animais. A carne suína, por exemplo, é a mais consumida no mundo e o Brasil é o quarto maior produtor, atrás apenas da China, União Europeia e Estados Unidos (ABIPECS, 2016).

Além de ser um grande produtor de energia renovável, o Brasil é também grande consumidor. Em 2015, por exemplo, a taxa de consumo permaneceu entre as mais elevadas do mundo, com 41,2\%, enquanto a média mundial foi de 13,5\% (figura 4). As fontes energéticas de origem renovável no Brasil foram as que mais tiveram destaque de crescimento em 2015 (figura 5). O gráfico mostra também que o petróleo é a maior fonte de energia do mundo e teve um decréscimo de 7,2\% em relação ao ano de 2014 no país, assim como o urânio, que é a principal matéria-prima para a energia nuclear, que diminuiu 4,5\% em comparação com o ano anterior.

Figura 4 - Gráfico de disponibilidade de energia no Brasil em 2015

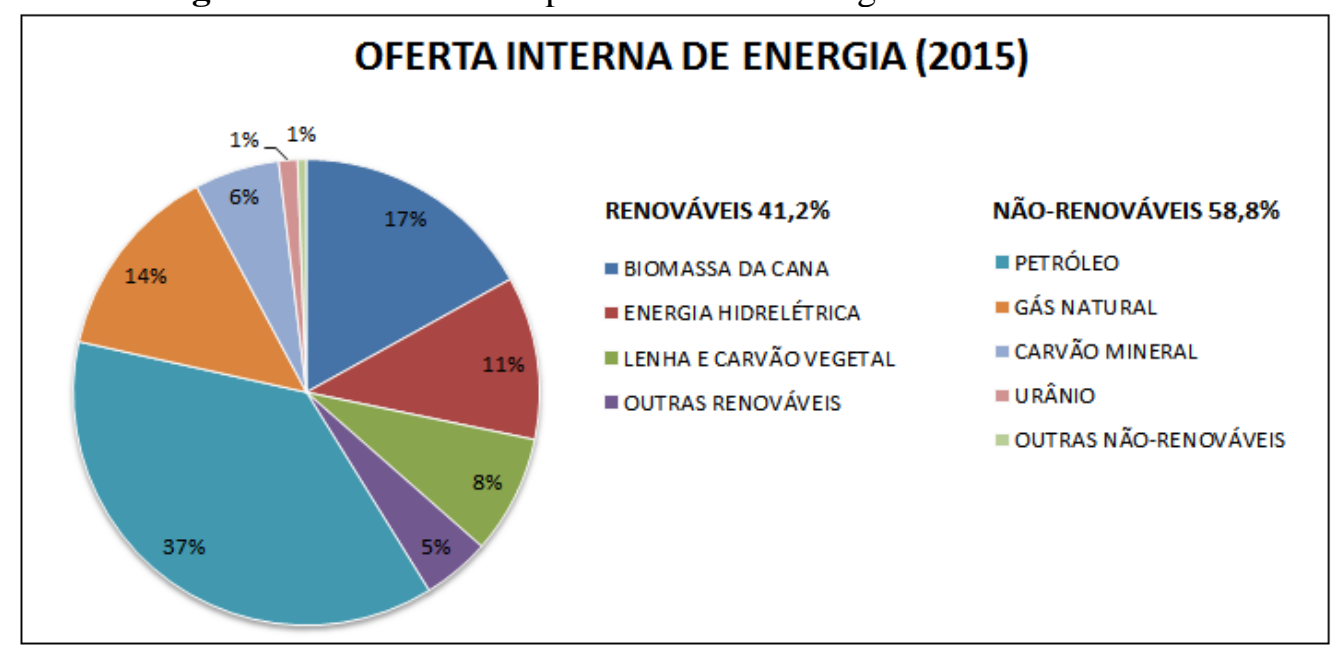

Fonte: MME (2016)

Adaptação: GUIMARÃES (2016) 
Figura 5 - Gráfico de oferta de energia no Brasil em 2015

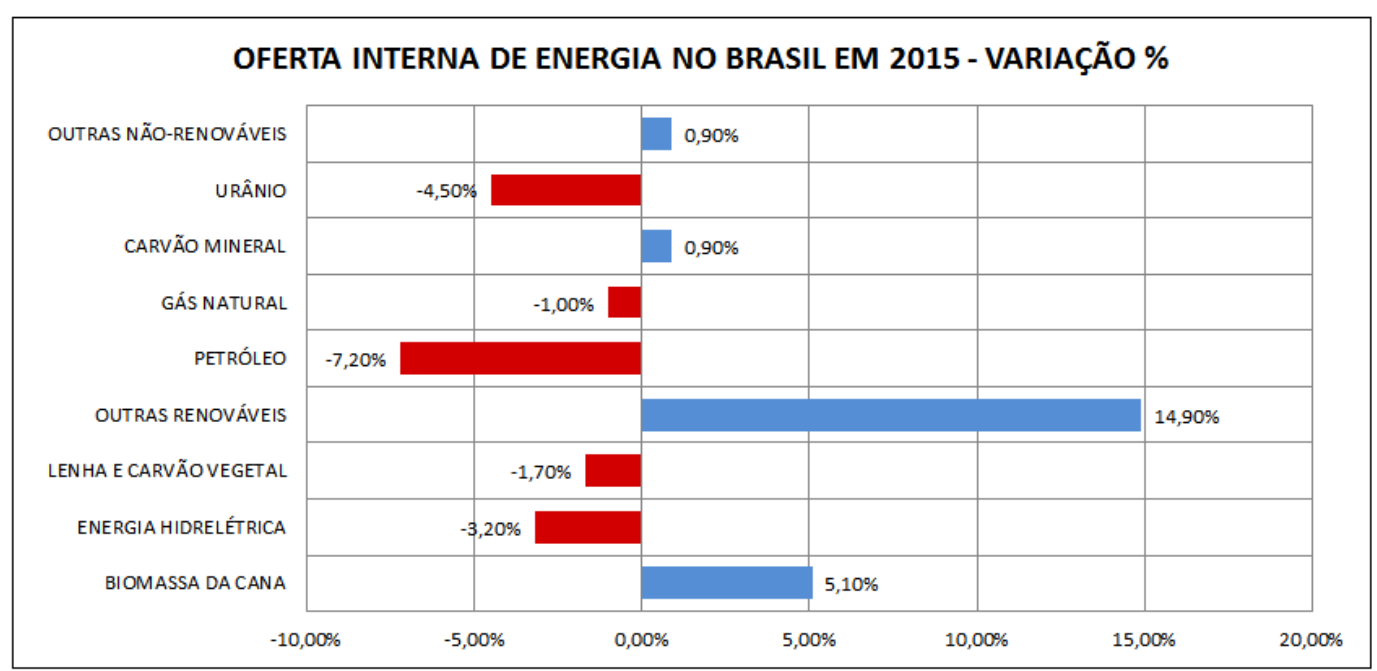

Fonte: MME (2016)

Adaptação: GUIMARÃES (2016)

\section{A REDE DE PRODUÇÃO DE BIOCOMBUSTÍVEIS NA REGIÃO SUL}

A implantação de uma usina de biocombustível, independente da matéria-prima utilizada, exige o atendimento às regulamentações e normas pré-estabelecidas. No Brasil, a atribuição de regularizar e fiscalizar as atividades relativas à produção, ao controle de qualidade, à distribuição, à revenda e à comercialização do biocombustível é da Agência Nacional do Petróleo, Gás Natural e Biocombustível - ANP, que detém os dados estatísticos de produção e comercialização em escala nacional.

Com base nos dados da ANP (2015a), constatou-se que a Região Sul do Brasil apresenta 48 usinas produtoras de biocombustíveis cadastradas (tabela 1) e em operação. No entanto, em sua base há outras usinas que estão em construção e outras plantas pilotos que estão sendo elaboradas, essas não foram consideradas nesta pesquisa.

Tendo como base os dados da tabela 1, é possível identificar que a maioria das usinas atua no território de forma isolada com uma única unidade produtora (35 no total), porém, em alguns casos, as usinas articulam-se em uma rede de produção dispersa pelo estado, como são os casos: da Usina de Açúcar Santa Terezinha Ltda que apresenta 8 unidades produtoras; da Renuka Vale do Ivaí com 2 unidades produtoras; e da Usina Alto Alegre S/A - Açúcar e Álcool com 3 unidades produtoras. 
Tabela 1 - Usinas de biocombustíveis na Região Sul

\begin{tabular}{|c|c|c|c|c|}
\hline & USINA & MATÉRIA-PRIMA & CIDADE & UF \\
\hline 1 & $\begin{array}{l}\text { OLFAR INDÚSTRIA E COMÉRCIO DE ÓLEOS } \\
\text { VEGETAIS LTDA }\end{array}$ & SOJA & ERECHIN & RS \\
\hline 2 & $\begin{array}{l}\text { BSBIOS INDÚSTRIA E COMÉRCIO DE BIODIESEL SUL } \\
\text { BRASIL S/A }\end{array}$ & SOJA & PASSO FUNDO & RS \\
\hline 3 & $\begin{array}{l}\text { BSBIOS MARIALVA INDÚSTRIA E COMÉRCIO DE } \\
\text { BIODIESEL SUL BRASIL LTDA }\end{array}$ & SOJA & MARIALVA & PR \\
\hline 4 & CAMERA AGROALIMENTOS S.A & SOJA & IJUÍ & RS \\
\hline 5 & OLEOPLAN S.A. - OLEOS VEGETAIS PLANALTO & SOJA & VERANÓPOLIS & RS \\
\hline 6 & OLEOPLAN S.A. - OLEOS VEGETAIS PLANALTO & SOJA & SÃO LEOPOLDO & RS \\
\hline 7 & $\begin{array}{l}\text { BIANCHINI S/A - INDÚSTRIA, COMÉRCIO E } \\
\text { AGRICULTURA }\end{array}$ & SOJA & CANOAS & RS \\
\hline 8 & FUGA COUROS & GORDURA BOVINA & CAMARGO & RS \\
\hline 9 & $\begin{array}{l}\text { BOCCHI IND COM TRANSP E BENEFICIAMENTO DE } \\
\text { CEREAIS LTDA }\end{array}$ & SOJA & IBIRAIARAS & RS \\
\hline 10 & ADM DO BRASIL LTDA & SOJA & JOAÇABA & $\mathrm{SC}$ \\
\hline 11 & POTENCIAL BIODIESEL LTDA & SOJA & LAPA & $\mathrm{PR}$ \\
\hline 12 & OLEOPLAN S.A. - OLEOS VEGETAIS PLANALTO & SOJA & PONTA GROSSA & $\mathrm{PR}$ \\
\hline 13 & $\begin{array}{l}\text { GRANOL INDÚSTRIA, COMÉRCIO E EXPORTAÇÃO } \\
\text { S.A. }\end{array}$ & SOJA & CACHOEIRA DO SUL & RS \\
\hline 14 & BIOPAR - BIOENERGIA DO PARANÁ LTDA & SOJA & ROLÂNDIA & $\mathrm{PR}$ \\
\hline 15 & TRES TENTOS AGROINDUSTRIAL S/A & SOJA & IJUÍ & RS \\
\hline 16 & CAMERA AGROALIMENTOS S.A & SOJA & ESTRELA & RS \\
\hline 17 & $\begin{array}{l}\text { BIG FRANGO INDÚSTRIA E } \\
\text { ALIMENTOS LTDA }\end{array}$ & $\begin{array}{l}\text { GORDURA } \\
\text { FRANGO }\end{array}$ & ROLÂNDIA & $\mathrm{PR}$ \\
\hline 18 & SABARALCOOL SA ACUÚCAR E ÁLCOOL & CANA-DE-AÇÚCAR & PEROBAL & $\mathrm{PR}$ \\
\hline 19 & $\begin{array}{l}\text { COOPERATIVA } \\
\text { PRODUTIVA }\end{array}$ & CANA-DE-AÇÚCAR & ASTORGA & PR \\
\hline 20 & DACALDA AÇÚCAR E ÁLCOOL LTDA & CANA-DE-AÇÚCAR & JACAREZINHO & $\mathrm{PR}$ \\
\hline 21 & $\begin{array}{l}\text { USI - USINAS SOCIAIS INTELIGENTES DESTILARIAS } \\
\text { SUSTENTÁVEIS S/A }\end{array}$ & CANA-DE-AÇÚCAR & SÃO VICENTE DO SUL & RS \\
\hline $\begin{array}{l}22 \\
23 \\
24 \\
25 \\
26 \\
27 \\
28 \\
29\end{array}$ & $\begin{array}{l}\text { USINA DE AÇÚCAR SANTA TEREZINHA LTDA } \\
\text { (USACUCAR) }\end{array}$ & $\begin{array}{l}\text { CANA-DE-AÇÚCAR } \\
\text { CANA-DE-AÇÚCAR } \\
\text { CANA-DE-AÇÚCAR } \\
\text { CANA-DE-AÇÚCAR } \\
\text { CANA-DE-AÇÚCAR } \\
\text { CANA-DE-AÇÚCAR } \\
\text { CANA-DEAÇÚCAR } \\
\text { CANA DE AÇÚCAR }\end{array}$ & $\begin{array}{l}\text { CIDADE GAÚCHA } \\
\text { MARINGÁ } \\
\text { PARANACITY } \\
\text { RONDON } \\
\text { TAPEJARA } \\
\text { IVATÉ } \\
\text { TERRA RICA } \\
\text { SÃO TOMÉ } \\
\end{array}$ & PR \\
\hline 30 & AMERICANA S.A & CANA-DE-ACÚCAR & $\begin{array}{l}\text { NOVA AMÉRICA DA } \\
\text { COLINA }\end{array}$ & PR \\
\hline $\begin{array}{l}31 \\
32\end{array}$ & RENUKA VALE DO IVAÍ & $\begin{array}{l}\text { CANA-DE-AÇÚCAR } \\
\text { CANA-DE-AÇÚCAR }\end{array}$ & $\begin{array}{l}\text { S. PEDRO DO IVAÍ } \\
\text { MARIALVA }\end{array}$ & PR \\
\hline 33 & $\begin{array}{l}\text { COOPERVAL COOPERATIVA } \\
\text { VALE DO IVAI LTDA }\end{array}$ & CANA-DE-AÇÚCAR & JANDAIA DO SUL & PR \\
\hline 34 & COMPANHIA AGRICOLA USINA JACAREZINHO & CANA-DE-AÇÚCAR & JACAREZINHO & $\mathrm{PR}$ \\
\hline $\begin{array}{l}35 \\
36 \\
37\end{array}$ & USINA ALTO ALEGRE S/A - AÇÚCAR E ÁLCOOL & $\begin{array}{l}\text { CANA-DE-AÇÚCAR } \\
\text { CANA-DE-AĆÚCAR } \\
\text { CANA-DE-AÇÚCAR }\end{array}$ & $\begin{array}{l}\text { COLOORADO } \\
\text { FLORESTÓPOLIS } \\
\text { SANTO INÁCIO }\end{array}$ & $\mathrm{PR}$ \\
\hline 38 & USINA DE AÇÚCAR E ÁLCOOL GOIOERE LTDA & CANA-DE-AÇÚCAR & MOREIRA SALES & $\mathrm{PR}$ \\
\hline 39 & AÇÚCAR E ALCOOL BANDEIRANTES S.A & CANA-DE-AÇÚCAR & BANDEIRANTES & \\
\hline 40 & $\begin{array}{l}\text { USINA CENTRAL DE PARANÁ S/A AGRICOLA } \\
\text { INDUSTRIAL E COMERCIAL }\end{array}$ & CANA-DE-AÇÚCAR & PORECATU & PR \\
\hline 41 & MELHORAMENTOS S/A & CANA-DE-ACUÚCAR & NOVA LONDRINA & $\mathrm{PR}$ \\
\hline 42 & COSTA BIOENERGIA LTDA - ME & CANA-DE-ACUUCAR & UMUARAMA & $\mathrm{PR}$ \\
\hline 43 & $\begin{array}{l}\text { COOPERATIVA AGRICOLA REGIONAL } \\
\text { PRODUTORES DE CANA LTDA (COOPCANA) }\end{array}$ & CANA-DE-AÇÚCAR & PARAÍSO DO NORTE & PR \\
\hline 44 & MELHORAMENTOS S/A & CANA-DE-ACUÚCAR & JUSSARA & $\mathrm{PR}$ \\
\hline 45 & CLARION S/A AGROINDUSTRIAL & CANA-DE-AÇÚCAR & IBAITI & $\mathrm{PR}$ \\
\hline 46 & $\begin{array}{l}\text { INDÚSTRIAS DE BEBIDAS REUNIDAS MORRO AZUL } \\
\text { LTDA - EPP }\end{array}$ & CANA-DE-AÇÚCAR & VENTANIA & $\mathrm{PR}$ \\
\hline 47 & $\begin{array}{l}\text { IMCOPA - IMPORTAÇÃO, EXPORTAÇÃO E INDÚSTRIA } \\
\text { DE ÓLEOS S/A }\end{array}$ & CANA-DE-AÇÚCAR & ARAUCÁRIA & PR \\
\hline 48 & CANEX BIOENERGIA LTDA & CANA-DE-AÇÚCAR & S VICENTE DO SUL & RS \\
\hline
\end{tabular}

Fonte: Agência Nacional de Petróleo, Gás natural e Biocombustível (ANP, 2015a; 2015b)

Adaptação: Guimarães, A. F. (2016) 
Para melhor compreender a dispersão espacial das usinas no território sul brasileiro, estas foram espacializadas no mapa exposto na figura 6. Com base no mapa, é possível observar que o estado que mais agrega usinas é o Paraná, com 35 unidades produtoras de biocombustíveis, as quais concentram-se especialmente nas porções norte e noroeste do estado, no entorno e ao norte do trópico de Capricórnio.

Figura 6 - Mapa da localização das usinas na Região Sul do Brasil

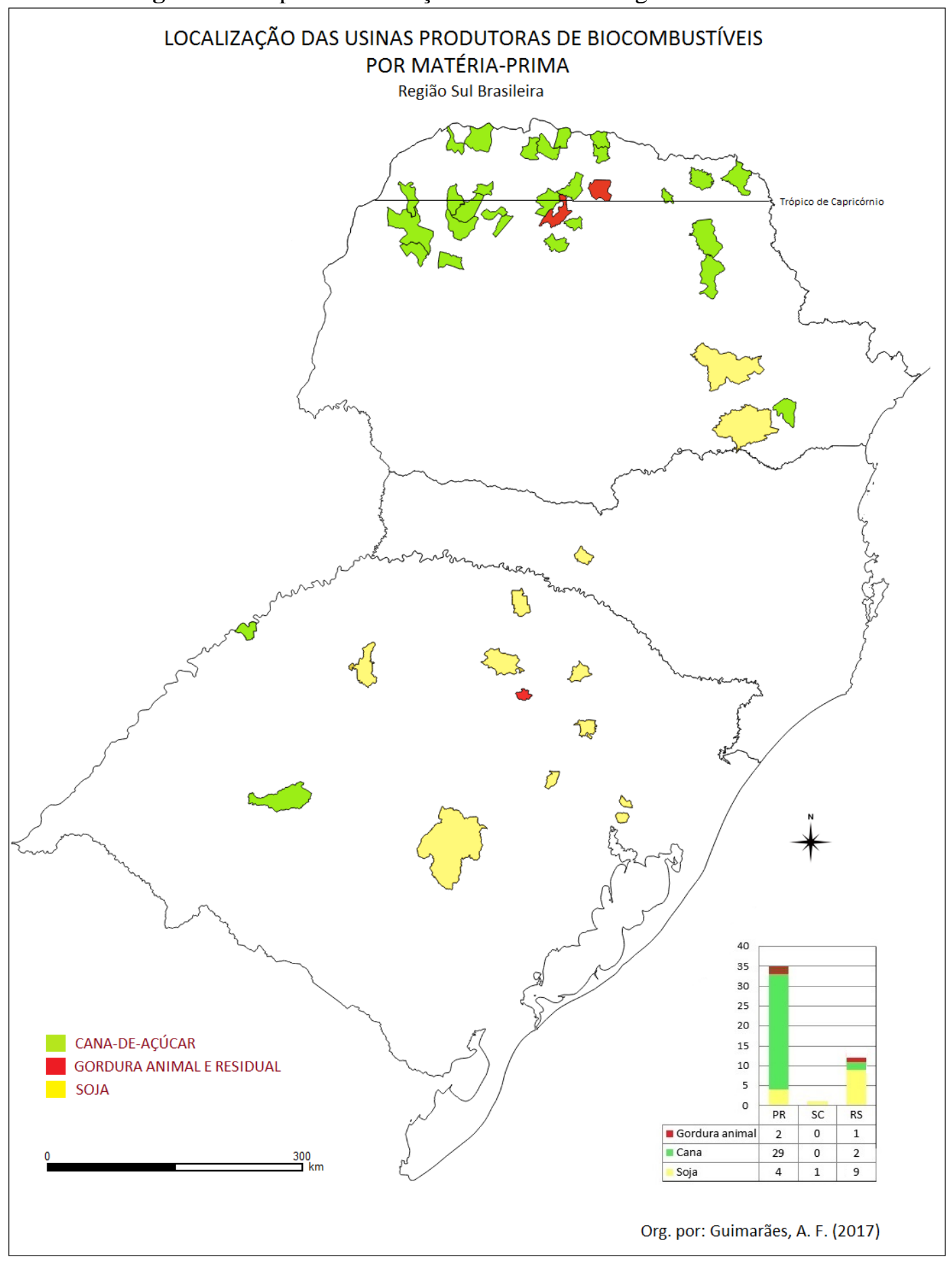

Fonte: Base cartográfica (IBGE, 2015a); dados das usinas produtoras (ANP 2015a; 2015b) Org.: GUIMARÃES (2017) 
O estado do Rio Grande do Sul possui 12 unidades produtoras de biocombustíveis, com maior concentração na porção centro-norte. Já o estado de Santa Catarina é o estado que menos produz biocombustível da Região Sul, com uma unidade produtora, localizada na porção central. Nos três estados a produção de biocombustíveis está concentrada em municípios interioranos, onde há oferta de matéria prima, mercado consumidor e condições para a produção, em contraposição às refinarias de petróleo brasileiras que se situam próximas ao litoral.

Com relação ao volume de produção, à matéria-prima utilizada e à categoria de biocombustível produzido, a maior parcela da produção na Região Sul é compreendida pelo etanol provido da cana-de-açúcar. Em 2015, foram produzidos 22.313,33 $\mathrm{m}^{3}$ diários de biocombustível, dos quais 66,19\% de etanol e 33,81\% de biodiesel (óleos vegetais e gordura animal).

A Região Sul, especialmente o estado do Paraná, é responsável pela produção de 8,3\% da oferta de etanol hidratado no país. Segundo a ANP (2015a), o estado produziu cerca de 694 milhões de litros em 2008, dos quais 560 milhões foram destinados à exportação. Tem-se, portanto, a cana-de-açúcar como a matéria-prima mais utilizada na produção de bioetanol. $\mathrm{O}$ estado do Paraná é o líder de produção na Região Sul, contando com 29 usinas. Já o Rio Grande do Sul possui apenas duas usinas e, em Santa Catarina, a produção de etanol é inexistente.

O estado do Rio Grande do Sul apresenta a maior parte da produção de biodiesel a partir da soja, com 10 usinas, destacando-se na Região Sul como o maior produtor. Na contramão, o estado de Santa Catarina é considerado o menor produtor de biocombustível da região, com apenas uma usina de biodiesel a partir da soja.

Cabe destacar que a soja e a gordura animal são as únicas matérias-primas utilizadas para a produção de biodiesel na área pesquisada, sendo 10 usinas de soja no Rio Grande do Sul, duas no Paraná e uma em Santa Catarina. A gordura animal se resume em uma usina de gordura de frango no Paraná e uma de gordura bovina no Rio Grande do Sul, mas a produção ainda é baixa.

Correlações entre a oferta de matéria-prima e a localização das usinas produtoras de biocombustíveis

A matéria-prima para a produção de biocombustíveis no Brasil é muito diversificada e cada região do país se destaca na produção a partir de um determinado produto. A Região Sul, objeto da pesquisa, apresenta características climáticas e relevos que propiciam a produção de 
bioetanol da cana-de-açúcar e do biodiesel a partir da soja, além de outros potenciais ainda pouco explorados.

O macroclima da Região Sul do Brasil é dividido em Tropical, na porção norte do estado do Paraná, e Subtropical, da parte central do Paraná em direção ao sul. A cultura canavieira, assim como as demais culturas de sacarose, necessita de grande irradiação solar e altas temperaturas, características do clima tropical, presente na região norte do Paraná. Decorrente deste fator, o estado é o maior produtor de etanol da Região Sul. Apesar de o Paraná ser o segundo maior produtor de etanol do país, a Região Sul está em quarto lugar na produção da cana no nível nacional, o que demonstra que essa cultura é em grande parcela destinada a produção do biocombustível. Desta forma, elaborou-se um mapa específico da produção de cana-de-açúcar do estado (figura 7), contendo a produção por toneladas de cada município, a fim de analisar a disponibilidade de matéria-prima para as usinas.

Figura 7 - Mapa de produção de cana-de-açúcar no estado do Paraná por tonelada

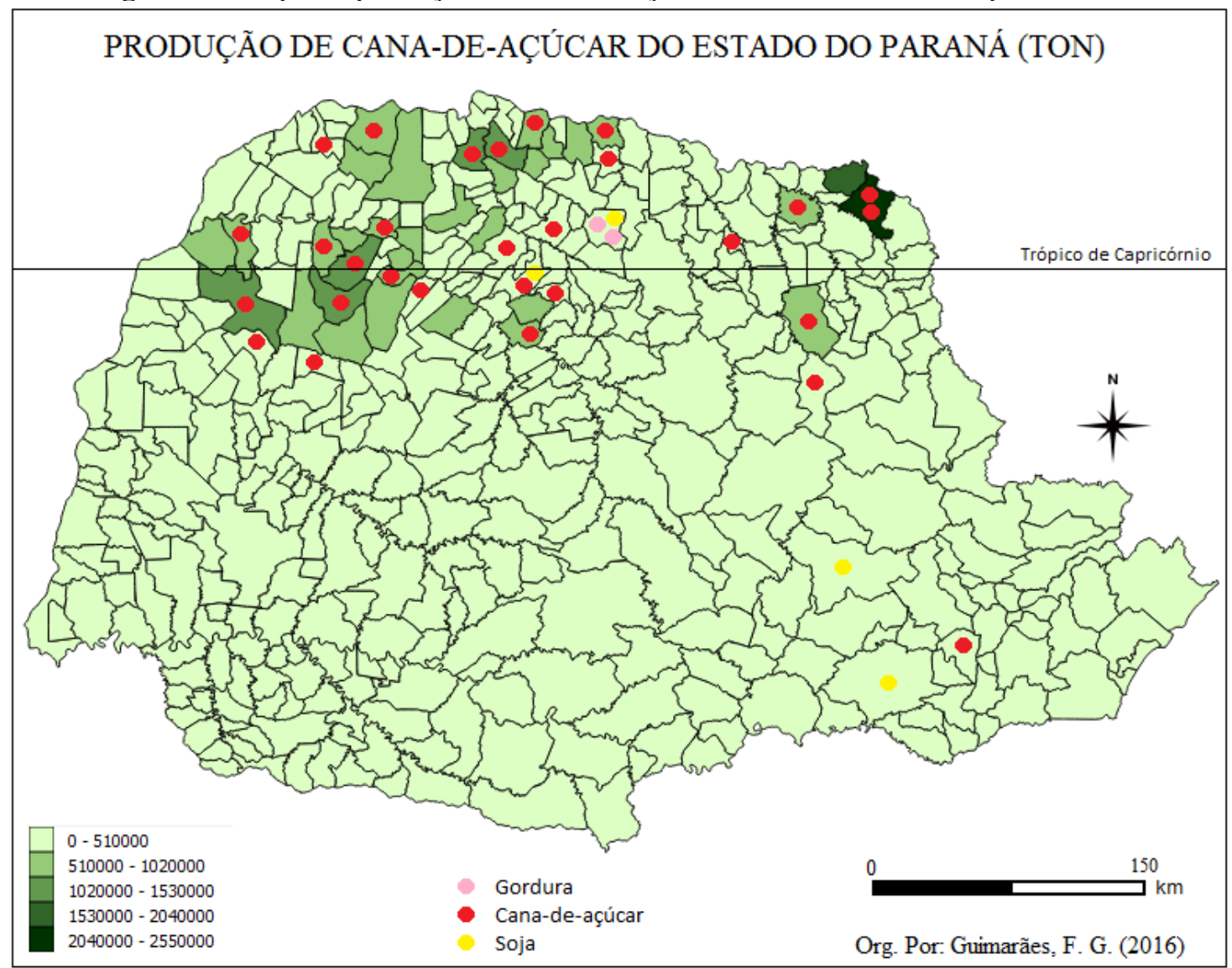

Fonte: Base cartográfica (IBGE, 2015a); dados de produção agrícola municipal (IBGE, 2015b) Org.: GUIMARÃES (2016)

Conforme visualizado no mapa, é notável que a maior produção de cana-de-açúcar do estado do Paraná se encontra próxima às usinas produtoras de bioetanol, sobretudo, nas porções 
nordeste e noroeste. O município de Jacarezinho é o maior produtor do estado com mais de 2,5 milhões de toneladas por ano, seguido por Cambará, Rondon, Colorado, Umuarama, Tapejara e Paranacity, essas por sua vez, produzem entre 100 milhões e 200 milhões de toneladas anualmente.

Estes municípios estão localizados na porção do estado com o clima classificado em Cfa segundo Köppen, este clima é subtropical com verões quentes e chuvas bem distribuídas durante todo o ano com temperaturas médias anuais acima de $22^{\circ} \mathrm{C}$, abrangendo todo o nordeste, norte, noroeste, oeste e sudoeste do estado. Já nas regiões dos primeiro e segundo planaltos paranaenses, está localizada a maior parte dos municípios que não produzem canade-açúcar no estado, devido à alta altitude e clima mais frio, classificado em $\mathrm{Cfb}$ segundo Köppen, este clima é temperado, caracterizado por possuir verões amenos, geadas frequentes em meses de inverno e temperaturas médias anuais não ultrapassando $18^{\circ} \mathrm{C}$, abrangendo as microrregiões de Curitiba, Ponta Grossa, Guarapuava, União da Vitória e Palmas (IAPAR, 1998).

Já com relação à soja, a planta se adapta facilmente em climas diversos e, mesmo sendo o Paraná o segundo maior produtor da planta do país, a produção de biodiesel a partir dela é bem inferior à produção gaúcha. A Região Centro-Oeste é a maior produtora de soja do Brasil, seguida da Região Sul. A Região Sudeste é pouco expressiva na produção de soja, pois a maior parte de sua agricultura é destinada à cana-de-açúcar e outros cultivos (SEAB, 2015). As Regiões Norte e Nordeste possuem características edafoclimáticas pouco propícias a produção da cultura: a Região Norte por sofrer com altas umidades provindas da Amazônia; e a Região Nordeste pelas altas temperaturas e baixo regime de chuva (clima semiárido). A produção por estado está ilustrada na figura 8.

Com relação à distribuição estadual da produção da soja (figura 8), o estado do Mato Grosso é o maior produtor brasileiro, seguido pelo Paraná e Rio Grande do Sul. Ou seja, dos três estados da Região Sul, dois são líderes nacionais de produção. No entanto, a maior parcela da produção paranaense (80\%) é destinada à exportação, principalmente para o mercado chinês e a produção de biodiesel a partir da soja é muito baixa. O Rio Grande do Sul é responsável pela contribuição de $76,73 \%$ de toda produção de biodiesel da Região Sul do Brasil, enquanto o Paraná produz 16,57\% e Santa Catarina apenas 6,7\%. Dado que se contrapõe em relação à produção de etanol, o Paraná produz 99,58\% de toda produção sul brasileira, o Rio Grande do Sul produz somente $0,42 \%$, e no estado de Santa Catarina a produção é inexistente. 
Figura 08 - Produção de soja por estado em 2015

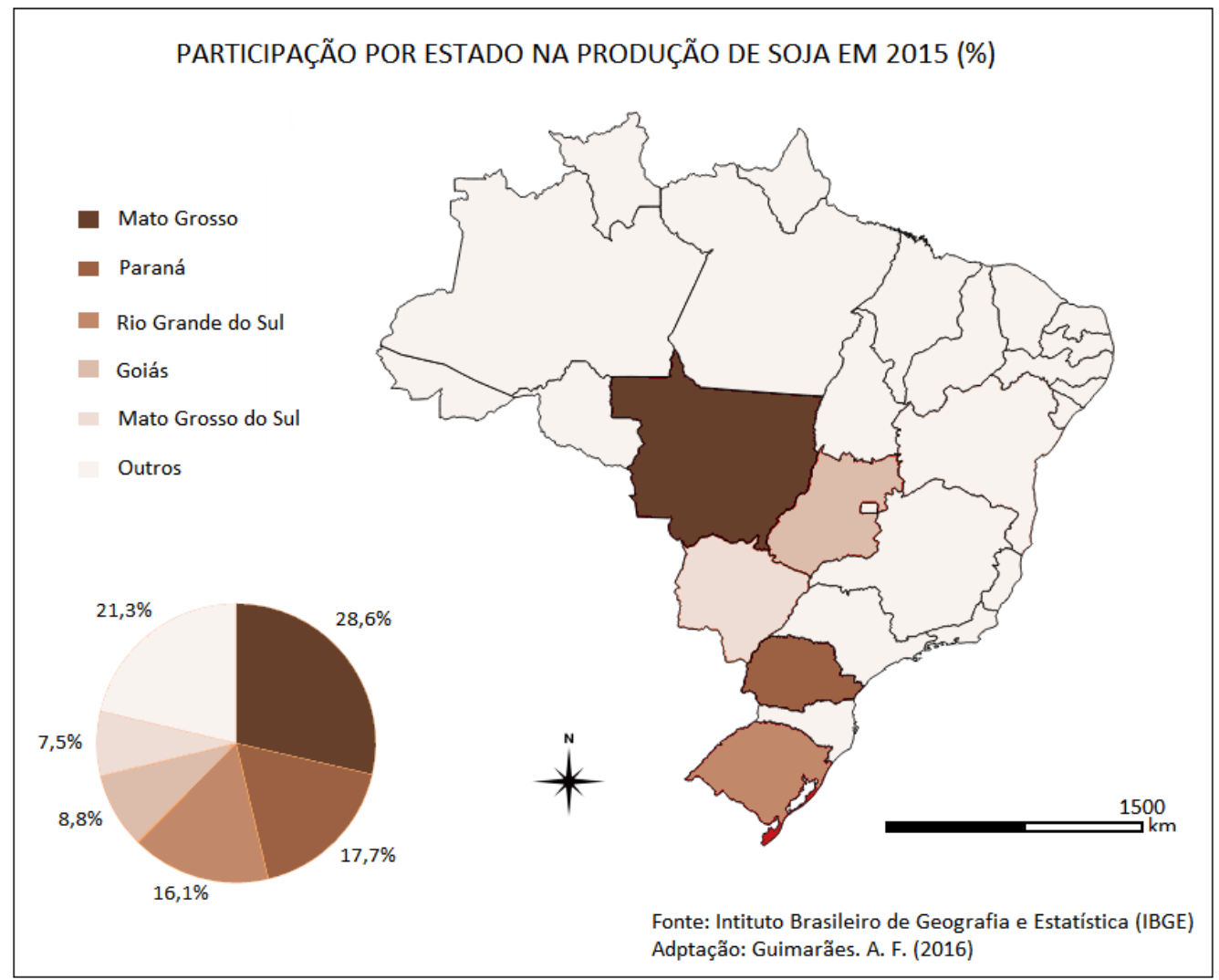

Fonte: Base cartográfica (IBGE, 2015a); dados de produção agrícola estadual (IBGE, 2015a) Org.: GUIMARÃES (2016)

É visível a discrepância entre a produção de bioetanol e biodiesel na Região Sul do Brasil. A cana-de açúcar lidera o mercado nacional de biocombustíveis e isso não é diferente na Região Sul. Já com relação aos biodieseis, a soja é a matéria-prima mais utilizada para esse fim, sendo responsável por 95,98\% de toda a produção, enquanto as gorduras representam apenas 4,02\%. A cana-de-açúcar é predominante no norte do estado do Paraná e a soja nos estados do Paraná e do Rio Grande do Sul.

O estado de Santa Catarina é o menor produtor tanto de cana-de-açúcar e da soja do sul brasileiro. A soja é a única matéria-prima utilizada na produção de biodiesel no estado (figura 9). A partir da figura, pode-se observar que a produção de soja em grãos se dá em todo o estado e o que destaque maior é para o município de Campos Novos, limítrofe com Joaçaba, onde se localiza a única usina de biocombustíveis do estado. A região oeste do estado é caracterizada pela agropecuária, sendo visível a discrepância com a porção leste, onde predomina a produção industrial e as atividades turísticas. 
Figura 9 - Mapa de produção de soja em grãos em Santa Catarina em 2012 por toneladas

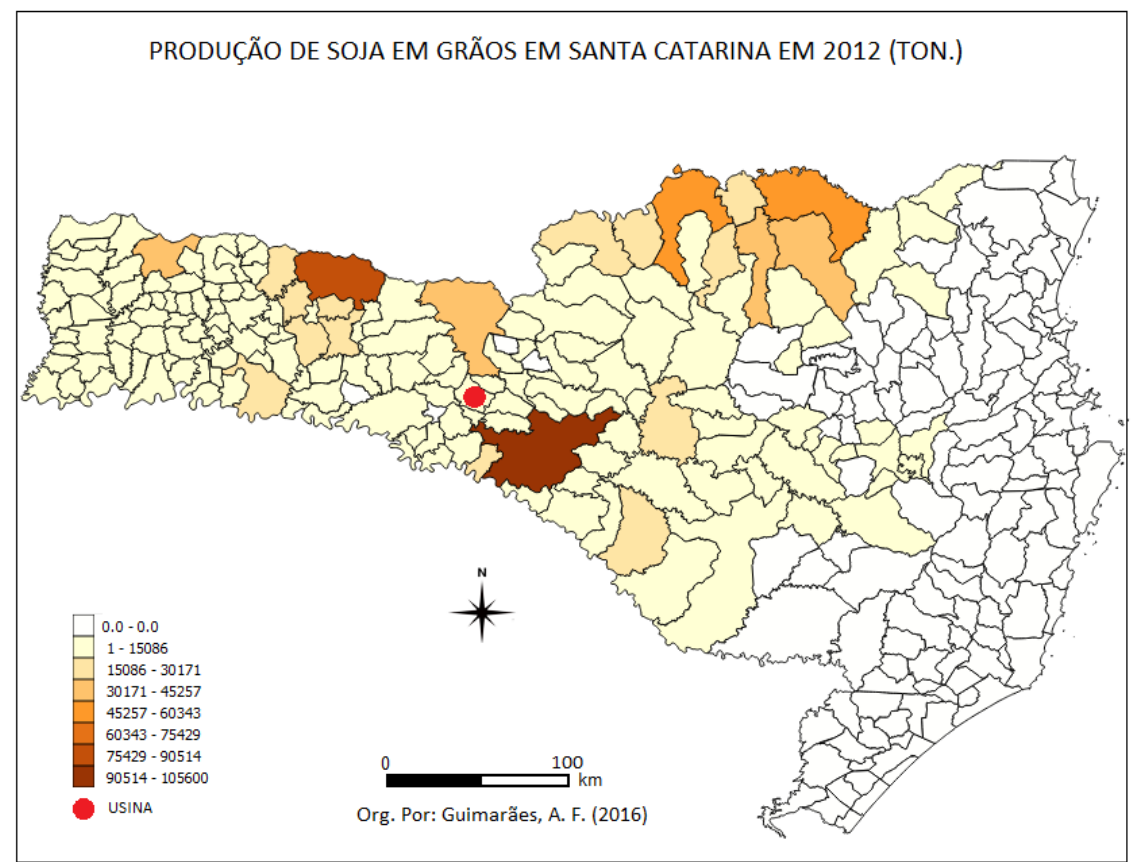

Fonte: Base cartográfica (IBGE, 2015a); dados de produção agrícola municipal (IBGE, 2015b) Org.: GUIMARÃES (2016)

O Rio Grande do Sul é o segundo maior produtor de soja da Região Sul. Por esse fator, em quase sua totalidade, as usinas produtoras de biocombustíveis do estado utilizam o grão como matéria-prima, como pode ser observado na figura 10. As usinas estão posicionadas no estado próximas aos municípios de maior produção da soja.

A Região Sul se destaca na produção de carnes. O estado do Paraná é o primeiro maior produtor aviário do Brasil. Santa Catarina ocupa o segundo lugar e o Rio Grande do Sul o terceiro lugar no ranking. Isso significa que o território em questão é o maior produtor de aves do país, porém, o investimento na gordura aviária como matéria-prima para a produção de biodiesel é muito pequeno.

Com relação à carne suína, o Rio Grande do Sul é o maior produtor nacional, seguido de Santa Catarina. Já o Paraná ocupa a sexta posição da lista. Dois dos três estados da Região Sul são os maiores produtores da carne suína do Brasil, demonstrando que, somando-se a quantidade de gordura aviária com a gordura suína, o potencial de produção de biocombustível a partir da gordura é alto, porém pouco explorado. Já com relação à carne bovina, ao contrário da carne suína e de frango, a Região Sul não está entre os primeiros lugares no ranking dos dez maiores produtores. Os estados do Paraná e do Rio Grande do Sul ocupam o nono e o décimo lugar, enquanto Santa Catarina não aparece na lista. Grande parte dos resíduos do abate dos 
animais é destinada à produção de sabão, indústria de cosméticos, ração e suplemento para granjas, entre outros produtos.

Figura 10 - Mapa de produção de soja em grãos no Rio Grande do Sul em 2007 por toneladas

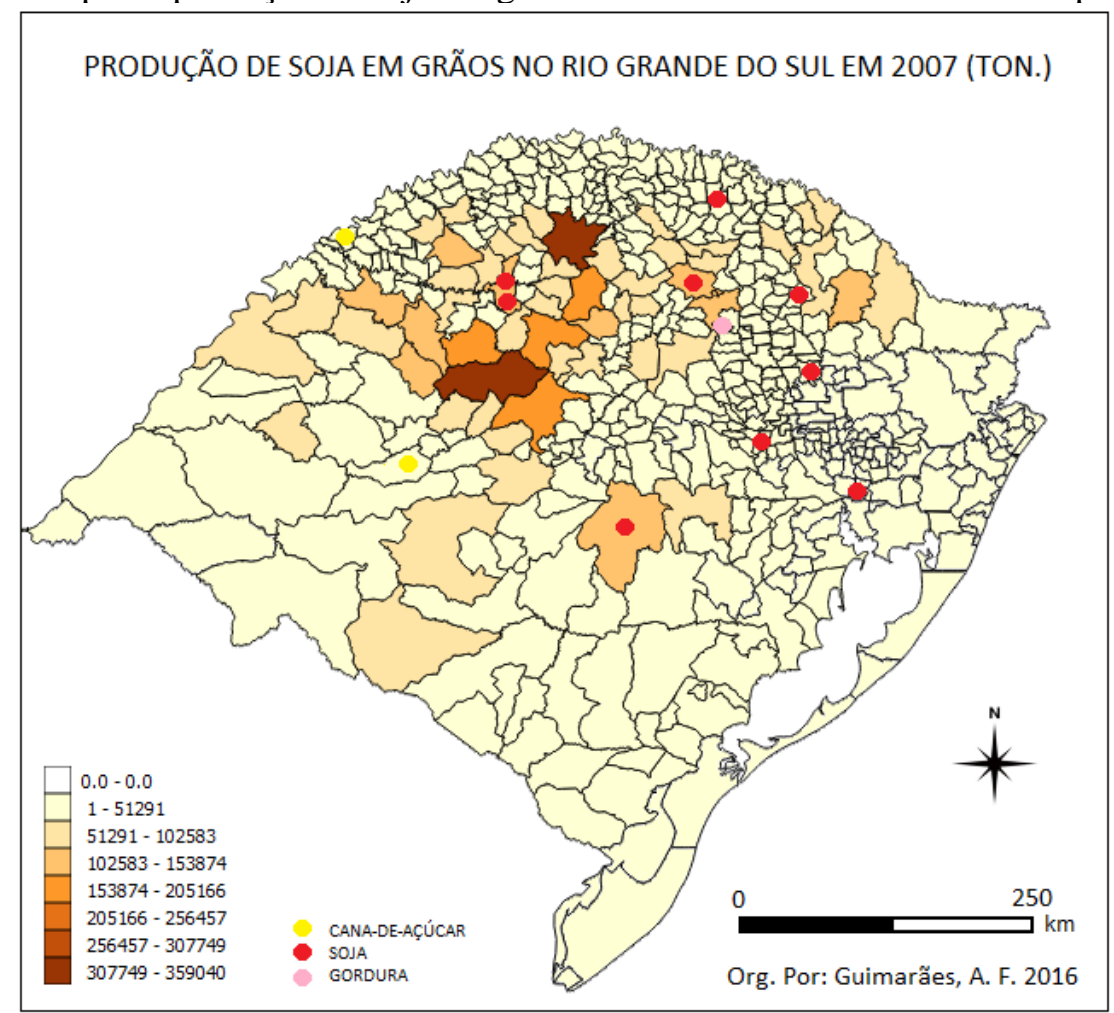

Fonte: Base cartográfica (IBGE, 2015a); dados de produção agrícola municipal (IBGE, 2015b) Org.: GUIMARÃES (2016)

Com esses dados, é possível notar que a Região Sul é a segunda maior produtora de soja do Brasil e a maior em produção aviária e suína, apresentando desta forma, grande potencial para a produção de biodiesel a partir de gordura vegetal e animal. A região oeste do Paraná é a maior em produção de frangos e suínos do estado, com alto potencial de produção de biodiesel com gordura animal. No entanto, a maior parte da gordura retirada dos animais abatidos é destinada de forma incorreta. Conforme a tabela 2, quase dois bilhões de animais são abatidos anualmente somente no estado.

Tabela 2 - Número de abates por ano no Paraná

\begin{tabular}{c|c|c}
\hline TIPO DE ANIMAL & 2014 (N. ${ }^{\circ}$ DE ABATES) & 2015 (N. ${ }^{\circ}$ DE ABATES) \\
\hline BOVINOS & 1.450 .453 & 1.246 .716 \\
SUÍNOS & 6.920 .787 & 7.716 .969 \\
AVES (FRANGO) & 1.643 .383 .540 & 1.772 .546 .336 \\
\hline TOTAL & 1.651 .754 .780 & 1.781 .510 .021 \\
\hline
\end{tabular}

Fonte: SEAB (2014)

Conforme a Empresa Brasileira de Estudos Agropecuários (EMBRAPA, 2016), cerca de 355 mil toneladas de graxa suína são provenientes de abatedouros todos os anos no Brasil.

\begin{tabular}{lll}
\hline Guimarães, Colavite e Silva, 2019 & ISSN 0104-5490
\end{tabular}


Essa graxa é destinada principalmente à produção de ração animal. Em média, cada suíno produz cerca de oito quilos de banha e cada quilo pode ser convertido em até $750 \mathrm{ml}$ de biodiesel, ou seja, cada suíno pode gerar até seis litros de biocombustível. Levando em consideração o número de abates em 2015 de 7.716.969 de cabeças, o rendimento de biodiesel provido das granjas de suínos ultrapassaria 46 milhões de litros.

A carne bovina é a segunda carne mais consumida no mundo. Cada animal gera cerca de 18 quilos de sebo após o abate e cada quilo de sebo pode ser transformado em até $800 \mathrm{ml}$ de biodiesel. Sendo assim, resultando 14,4 litros por cabeça. Considerando que no Paraná foram 1.246.716 abates em 2015, se todo o sebo tivesse sido convertido em biocombustível, o sebo bovino teria rendido 17,5 milhões de litros. Já as aves, 218 mil toneladas de óleo são provenientes de suas gorduras. Porém, o potencial dessas gorduras não é totalmente explorado.

Nota-se que a produção do biodiesel através da gordura é muito pequena se comparado à produzida a partir da soja. Apenas uma usina no Paraná utiliza a gordura de frango como matéria-prima para a produção. A usina faz parte de um grande abatedouro de aves que passou a produzir biocombustível da gordura que antes era descartada. Sua produção é de seis metros cúbicos $\left(6 \mathrm{~m}^{3}\right)$ por dia. $\mathrm{O}$ mesmo ocorre com a usina gaúcha que utiliza a gordura bovina para produzir biocombustível. A produção dela a partir da gordura dos animais abatidos pode chegar a cerca de $300 \mathrm{~m}^{3}$ de biocombustível diariamente.

Com relação à gordura residual, essa matéria-prima se mostra inexistente nos dados obtidos, pois, o registro na ANP autoriza que uma determinada usina produza uma quantidade de biocombustível relacionada com a capacidade de produção instalada.

\section{CONSIDERAÇÕES FINAIS}

A Região Sul do Brasil possui 48 usinas cadastradas na Agência Nacional do Petróleo, Gás Natural e Biocombustível (ANP). No estado do Paraná, apresentam-se 35 delas, sendo 29 usinas de etanol de cana-de-açúcar, quatro usinas de biodiesel de soja e duas usinas a partir da gordura (uma animal e outra residual). Já no estado do Rio Grande do Sul apresentam-se 13, sendo 10 usinas de biodiesel a partir da soja, duas usinas de etanol de cana-de-açúcar e uma usina de biodiesel de gordura animal. E no estado de Santa Catarina apresenta-se apenas uma usina produtora de biodiesel de soja.

A produção de biocombustíveis na região em estudo utiliza basicamente a soja e a cana-de-açúcar como matérias-primas. As gorduras animal e residual seguem com uma produção muito baixa, não apresentando escala comercial. Comparando os três estados, o 
Paraná é o maior produtor de etanol a partir da cana-de-açúcar, o Rio Grande do Sul o maior produtor de biodiesel a partir da soja e Santa Catarina é o estado que menos se destaca no cenário bioenergético, com apenas uma usina de biodiesel de soja.

A produção de biodiesel a partir da gordura animal, além de reutilizar os resíduos sólidos resultantes do abate, não compete com os alimentos, como no caso da cana-de-açúcar e da soja. O sebo, que antes era um passivo ambiental, agora é utilizado como matéria-prima de baixo custo e com características semelhantes aos óleos vegetais, no que diz respeito as suas propriedades químicas. A Região Sul dispõe de um amplo mercado do subproduto animal oriundo dos abates em frigoríficos, porém, é um mercado pouco explorado.

De forma geral, não somente a Região Sul, mas o Brasil como um todo é um grande produtor de animais, gerando assim, grande quantidade de gordura animal após o abate. O que torna preocupante é a falta de incentivo às indústrias e de profissionais que sejam capazes de produzir em grandes quantidades esse combustível ecologicamente correto e sustentável.

\section{REFERÊNCIAS}

ABIPECS - Associação Brasileira da Indústria Produtora e Exportadora de Carne Suína. Produção de carne do Rio Grande do Sul. 2016. Disponível em: <http://abpabr.com.br/setores/suinocultura/publicacoes/relatorios-anuais>. Acesso em: 09 de setembro de 2016.

ANP - Agência Nacional de Petróleo, Gás Natural e Biocombustível. Produção anual de etanol. 2015a. Disponível em: < <http://www.anp.gov.br/wwwanp/producao-debiocombustiveis/etanol>. Acesso em: 15 de abril de 2016.

Produção anual de biodiesel. 2015b. Disponível em: <http://www.anp.gov.br/wwwanp/dados-estatisticos>. Acesso em: 15 de abril de 2016.

BIODIESELBR. História do biocombustível. 2015. Disponível em: <https://www.biodieselbr.com/biodiesel/historia/biodiesel-historia.htm>. Acesso em $09 \mathrm{de}$ setembro de 2016.

BIODIESELBR. Maiores produtores de biocombustíveis do mundo. 2011. Disponível em: < http://www.biodieselbr.com/noticias/em-foco/brasil-produtores-biocombustiveis-mundo300311.htm >. Acesso em: 23 de maio de 2016.

COSTA, P. Análise geo-histórica da indústria de refino de petróleo no Brasil. In: VIDEIRA, S.L.; COSTA, P.A.; FAJARDO, S. (Orgs.). Geografia econômica: (re) leituras contemporâneas. Rio de Janeiro: Letra Capital, 2011, p. 21-46. (Série Acadêmica).

EMBRAPA - Empresa Brasileira de Pesquisa Agropecuária. Cana-de-açúcar. 2009. Disponível em: < http://www.agencia.cnptia.embrapa.br/gestor/cana-deacucar/arvore/CONTAG01_1_711200516715.html >. Acesso em: 09 de setembro de 2016.

Gordura animal. [s.d.]. Disponível em: $\overline{<\mathrm{http} / / / w w w . a g e n c i a . c n p t i a . e m b r a p a . b r / g e s t o r / a g r o e n e r g i a / a r v o r e / C O N T 000 f j 1 o m 7 k f 02 w y i v ~}$ 802hvm3jholyoom.html>. Acesso em: 06 de outubro de 2016. 
FERRARI et. al. Biodiesel de soja - taxa de conversão em ésteres etílicos, caracterização físico-química e consumo em gerador de energia. In: Química nova, São Paulo, v. 28, n. 1, p. 19-23, 2005.

FREITAS, S. M. de; FREDO, C. E. Fontes energéticas e protocolo de Kyoto: a posição do Brasil. In: Informações econômicas, São Paulo, v. 35, n. 5, p. 77-82, maio 2005.

HALL, D. O; HOUSE, J. Biomass energy in western Europe to 2050. In: Land use policy, [s.1.], v. 12, p. 37-48, 1995.

HOLANDA, A. (Relator). Biodiesel e inclusão social. Brasília: Câmara dos Deputados, Coordenação de Publicações, 2004.

IAPAR - Instituto Agronômico do Paraná. Climas do Paraná. 1998. Disponível em: <http://www.iapar.br/modules/conteudo/conteudo.php?conteudo=863>. Acesso em: $27 \mathrm{de}$ setembro de 2016.

IBGE - Instituto Brasileiro de Geografia e Estatística. Bases cartográficas estaduais. 2015a. Disponível em: <http://mapas.ibge.gov.br/bases-e-referenciais/bases-cartograficas/malhasdigitais>. Acesso em: 25 de maio de 2016.

Produção agrícola municipal. Culturas temporárias e permanentes. 2013. Disponível em:

<ftp://ftp.ibge.gov.br/Producao_Agricola/Producao_Agricola_Municipal_[anual]/2013/pam20 13.pdf>. Acesso em: 27 de setembro de 2016.

Produção agrícola municipal. 2015b. Disponível em: <https://cidades.ibge.gov.br/ >. Acesso em: 05 de setembro de 2016.

KNOTHE, G. Perspectivas históricas de los combustibles diesel basados em aceites vegetales. In: Revista A\&G, Rosário, v. 47, Tomo XII, n. 2, p. 222-226, 2002.

KOHLHEPP, G. Análise da situação da produção de etanol e biodiesel no Brasil. In: Estudos avançados, São Paulo, v. 24, n. 68, 2010.

LEITE, R. C. de C.; LEAL, M. R. L. V. O biocombustível no Brasil. In: Revista novos estudos, São Paulo, n. 78, p. 15-21, 2007.

MME - Ministério de Minas e Energias. Balanço energético nacional. 2016. Disponível em: $<$ https://ben.epe.gov.br/downloads/S\%C3\%ADntese\%20do\%20Relat\%C3\%B3rio\%20Final_ 2016_Web.pdf>. Acesso em: 25 de agosto de 2016.

SASTRY, S. V. A. R.; MURTHY, C. V. R. Prospects of biodiesel for future energy security. In: Elixir international jornal, Salem, n. 53, 2012.

SEAB - Secretaria de Estado da Agricultura e do Abastecimento. Soja, análise de conjuntura agropecuária. $2015 . \quad$ Disponível em: $<$ https://bay175.mail.live.com/mail/ViewOfficePreview.aspx?messageid=mg3gkJkPeL5hGLn $\mathrm{gAhW}$ tbn $1 \mathrm{~A} 2 \&$ folderid $=$ flinbox $\&$ attindex $=0 \& \mathrm{cp}=-1 \&$ attdepth $=0 \& \mathrm{n}=67571335>$. Acesso em : 25 de setembro de 2016.

Produção de carne bovina no Paraná. 2014. Disponível em: <http://www.agricultura.pr.gov.br/arquivos/File/deral/nppr.pdf >. Acesso em: 09 de setembro de 2016.

TOLMASQUIM, M.T. et al. Matriz energética brasileira: uma prospectiva. In: Novos estudos, São Paulo, n. 79, p. 47-69, nov. 2007 
Revista de Geografia (Recife) V. 36, Nº 3, 2019

ÚNICA - União das Indústrias da Cana-de-açúcar -. Setor sucroenergético: mapa da produção. 2009. Disponível em <http://www.unica.com.br>. Acesso em: 23 de julho de 2016. 